\title{
Resistance Performance Forecast of Trimaran Based on Multiple Regression Analysis
}

\author{
Xiao ying $\mathrm{Xu}{ }^{1}$, Chao ying Meng ${ }^{2}{ }^{*}$, and KUAN Wang ${ }^{3}$ \\ ${ }^{1,2}$ Wenhua College, Wuhan, 430074, China \\ ${ }^{3}$ China Classification Society Wuhan Branch, Wuhan, 430033, China
}

\begin{abstract}
Based on the multiple linear regression of the relevant data of 29 ships in the basic database, including cargo ship, oil ship, container ship and chemical ship, etc, the empirical estimation formula of resistance coefficient of single ship under different Fr was obtained. The feasibility of applying the above regression formula to the prediction of the resistance performance of the trimaran based on DTMB5415 is verified by comparison with CFD simulation data. This method has a strong engineering applicability and provides a new idea for the study of computer-aided layout optimization of the trimaran.
\end{abstract}

\section{Introduction}

In recent years, research on trimaran, especially its layout optimization is taking attention to a growing number of scholars. Many studies have achieved remarkable results, but they generally use CFD technology based on viscosity theory, which takes a long time to calculate. They are not suitable to be extended to a large number of conversion in the layout and speed. In response to the above problems, this paper performed multiple linear regression based on the relevant data of 29 cargo ships, oil tankers, container ships and chemical tankers, and obtained the empirical estimation formula for the resistance coefficient of monohull under different Fr. Using CFD to simulate the trimaran verified the feasibility of applying the regression formula, which predicted the resistance performance of the trimaran. This paper provides a new idea for computer-aided trimaran layout optimization research, which can be widely used preliminary prediction of the trimaran's performance.

\section{Regression principle}

Regression analysis is a method of statistical calculation. It starts from a set of observation data of independent variables and dependent variables. Finally, find a functional expression that approximates the statistical correlation between the independent and the dependent variables. In various regression analysis, linear regression is relatively common. And some nonlinear problems can also be transformed into linear regression problems through variable substitution. We called them generalized linear regression. It is:

$$
y=\beta_{0}+\beta_{1} x+\beta_{2} x^{2}+\cdots+\beta_{0} x^{m}+\varepsilon
$$

where ${ }^{\varepsilon}$ is error. When $x_{1}=x, x_{2}=x^{2}, \ldots, x_{m}=x^{m}$, equation (1) becomes:

$$
y=\beta_{0}+\beta_{1} x_{1}+\beta_{2} x_{2}+\cdots+\beta_{0} x_{m}+\varepsilon
$$

For a set of observations containing $\mathrm{n}$ data points $\left(\mathrm{x}_{\mathrm{i} 1}\right.$, $\mathrm{x}_{\mathrm{i} 2} \ldots \mathrm{x}_{\mathrm{im}}, \mathrm{y}_{\mathrm{i}}$,), the regression coefficients $\beta_{0}, \beta_{1} \ldots, \beta_{m}$ can usually be determined by the least square method to minimize the residual sum of squares, as shown in the following formula (3):

$$
Q=\sum_{i=1}^{n}\left[y_{i}-\left(\beta_{0}+\beta_{1} x_{i 1}+\beta_{2} x_{i 2}+\cdots+\beta_{0} x_{i m}\right)\right]^{2}
$$

After obtaining the regression coefficients, the significance of the regression model must be tested with using the $\mathrm{F}$ method. Firstly, define $\hat{y}=\beta_{0}+\beta_{1} x_{i 1}+\beta_{2} x_{i 2}+\cdots+\beta_{0} x_{i m}$ and $\bar{y}=\sum_{i=1}^{n} y_{i} / \mathrm{n}$. Secondly, put them into the following formula (4):

$$
\begin{gathered}
S S E=\sum_{i=1}^{n}\left[y_{i}-\hat{y}\right]^{2} \\
S S R=\sum_{i=1}^{n}[\bar{y}-\hat{y}]^{2} \\
S S T=\sum_{i=1}^{n}\left[y_{i}-\bar{y}\right]^{2}
\end{gathered}
$$

Where SSE is error square sum, SSR is regression squares sum, $\mathrm{SST}$ is total error square sum.

Finally, suppose $H_{0}: \beta_{0}=\beta_{1}=\ldots=\beta_{k}=0$. When $\mathrm{H}_{0}$ holds, the tested statistic $\mathrm{F}$ is shown in the following formula (5):

$$
F=\frac{S S R / m}{S S E /(n-m-1)} \sim F(m, n-m-1)
$$

The probability of test significance is $p=P(F(m, n-m-1)>F)$, when $p<\alpha$ ( $\alpha$ generally taken as 0.05 ) holds, the regression equation is 
significant. So, the smaller SSE, the higher the accuracy of the regression equation.

In addition to testing the overall significance, it is also necessary to test the significance of a single variable in the regression model. We can eliminate variables that have no significant impact and obtain the optimal equation. It can be carried out according to the following basic idea. Under a given limit, some variables are gradually introduced and deleted in the equation containing only constant. And a significance test is performed for each step. This process is repeated until there are no insignificant variables removed and introduced into the regression equation.

\section{Resistance performance of monohull}

\subsection{Sample database}

The database is composed of 29 inland vessels, including 17 cargo ships, 7 container ships and 5 petro-chemical ships. It can be supplemented in follow-up work. Because of the wide distribution range of the main dimension of each ship, basic data is so much. Due to limited space, Table 1 only gives the relevant parameters under $\mathrm{Fr}=0.22$.

\subsection{Sample regression analysis}

After selecting the regression variable, multiple linear regression and testing are repeated many times. The significance test result of residual resistance is obtained.

The root mean square error (RMSE) is 0.0878 , the statistical value $F$ is 10.9071 and the corresponding probability $\mathrm{p}$ is 0.0001 .

Since $\mathrm{p}$ is less than ${ }^{\alpha}$, it shows that the regression equation is highly significant. And RMSE $=0.0878$, indicaties that the regression effect is good. The final regression equation is as follows (6):

$$
\begin{aligned}
& C r=4.4284+7.3579\left(\frac{L}{B}\right)+5.1019\left(\frac{B}{T}\right)-95.2222\left(C_{b}\right) \\
& -9.6765\left(\frac{L}{B}\right)\left(C_{b}\right)-4.1209\left(\frac{B}{T}\right)\left(C_{b}\right)-0.1861\left(\frac{B}{T}\right)^{2} \\
& +110.4263\left(C_{b}\right)^{2}
\end{aligned}
$$

For the convenience of observation, the following Figure 1-3 respectively shows the comparison between the final regression result and the original $C_{r}$ about $L / B$, $\mathrm{B} / \mathrm{T}$ and $\mathrm{C}_{\mathrm{b}}$. It can be seen that the regression value and the original data are both in good agreement with the distribution trend and numerical value.

\begin{tabular}{|c|c|c|c|c|c|}
\hline 5 & 6.1617 & 4.8571 & 0.765 & 1.257 & 3.344 \\
\hline 6 & 5.9520 & 5.2142 & 0.801 & 1.75 & 3.825 \\
\hline 7 & 6.3023 & 5.375 & 0.831 & 2.415 & 4.421 \\
\hline 8 & 5.7129 & 3.0851 & 0.833 & 2.283 & 4.250 \\
\hline 9 & 5.1687 & 6.5 & 0.771 & 1.826 & 3.989 \\
\hline 10 & 6.1764 & 4.8571 & 0.766 & 1.201 & 3.288 \\
\hline 11 & 4.9843 & 6 & 0.769 & 1.965 & 4.208 \\
\hline 12 & 5.4044 & 5.6666 & 0.772 & 1.835 & 3.967 \\
\hline 13 & 5.838 & 4.7692 & 0.796 & 1.927 & 4.064 \\
\hline 14 & 5.9635 & 4.6666 & 0.843 & 3.110 & 5.199 \\
\hline 15 & 5.9714 & 5 & 0.833 & 2.459 & 4.547 \\
\hline 16 & 5.7661 & 4.8571 & 0.790 & 2.147 & 4.257 \\
\hline 17 & 5.2518 & 4.8571 & 0.784 & 2.262 & 4.403 \\
\hline 18 & 5.9147 & 5.0714 & 0.827 & 2.475 & 4.562 \\
\hline 19 & 6.0421 & 4.6666 & 0.782 & 2.104 & 4.188 \\
\hline 20 & 5.9057 & 4.3783 & 0.842 & 2.932 & 4.977 \\
\hline 21 & 5.4122 & 5.1034 & 0.785 & 2.51 & 4.621 \\
\hline 22 & 5.5789 & 4.3428 & 0.807 & 2.643 & 4.727 \\
\hline 23 & 5.1093 & 6.4 & 0.809 & 2.246 & 4.419 \\
\hline 24 & 5.4737 & 4.875 & 0.782 & 2.536 & 4.617 \\
\hline range & $\begin{array}{c}4.98- \\
6.48 \\
\end{array}$ & $\begin{array}{c}3.01- \\
6.5 \\
\end{array}$ & $\begin{array}{c}0.75- \\
0.86 \\
\end{array}$ & $\begin{array}{l}1.20- \\
3.12 \\
\end{array}$ & $\begin{array}{c}3.34- \\
5.20 \\
\end{array}$ \\
\hline
\end{tabular}

Table.1 the Relevant Parameters under Fr $=0.22$

\begin{tabular}{|c|c|c|c|c|c|}
\hline num & $\mathrm{L} / \mathrm{B}$ & $\mathrm{B} / \mathrm{T}$ & $C_{b}$ & $C_{r}$ & $C_{t}$ \\
\hline 1 & 6.4779 & 4.25 & 0.796 & 2.062 & 4.133 \\
\hline 2 & 5.82 & 3.3333 & 0.83 & 1.962 & 3.946 \\
\hline 3 & 5.5740 & 3.0167 & 0.837 & 2.143 & 4.117 \\
\hline 4 & 5.6961 & 4.6428 & 0.750 & 2.105 & 4.234 \\
\hline
\end{tabular}

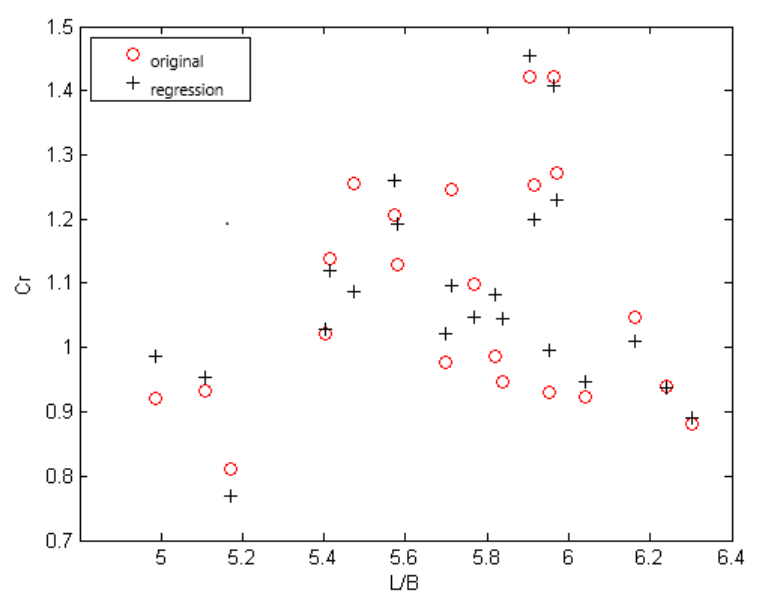

Fig. 1. Comparison between the Regression Result and the Original $\mathrm{Cr}$ about $\mathrm{L} / \mathrm{B}$, 
Table.2 Regression value and original test data under $\mathrm{Fr}=0.15$

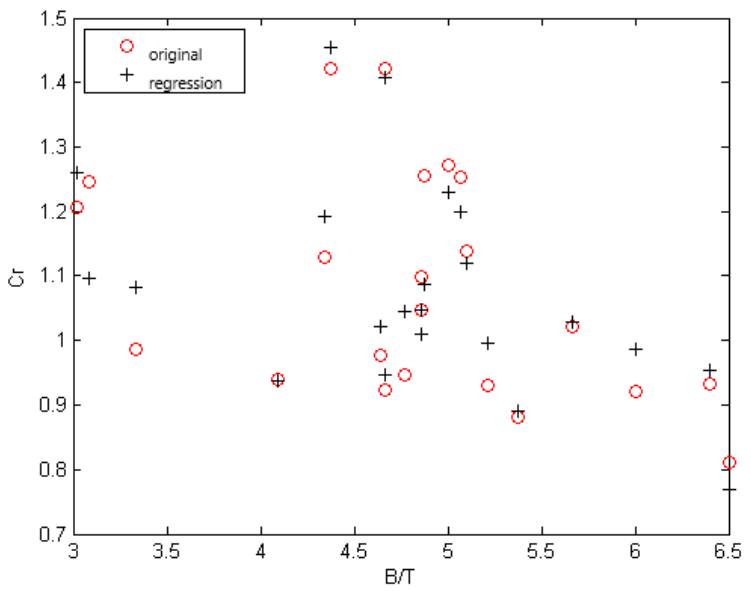

Fig. 2. Comparison between the Regression Result and the Original $\mathrm{Cr}$ about B/T

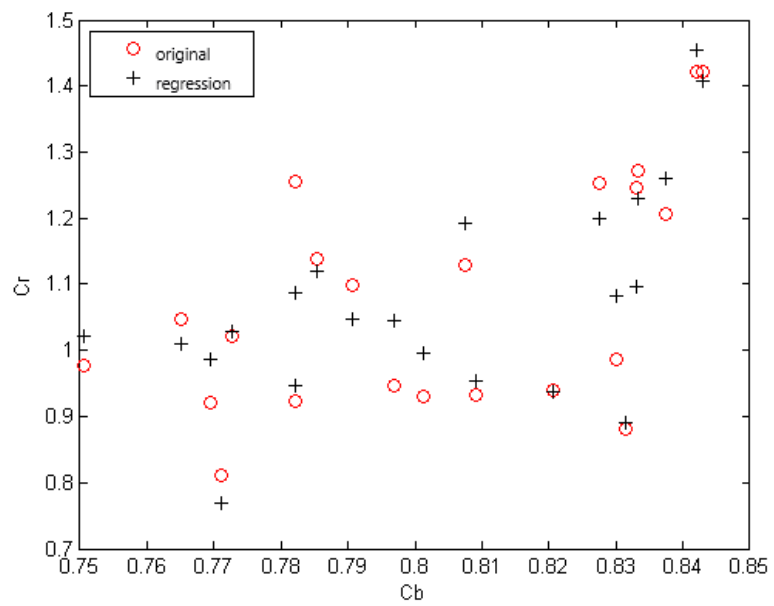

Fig. 3. Comparison between the Regression Result and the Original $\mathrm{Cr}$ about $\mathrm{Cb}$

The friction drag coefficient of the real ship can be calculated by the ITTC57 formula. Using the regression value of $\mathrm{Cr}$ obtained above, the total drag coefficient of the ship can be obtained. Table 2 is the error comparison between calculated $\mathrm{Ct}$ calculated by regression $\mathrm{Cr}$ and the original test data. As the rejection points of the sample data under different Fr may be different, the number column in the table is different according to different Fr.

Comparing it with the original experimental data, the error is within $\pm 5 \%$. It can be seen that the two data fits well, and the method has a certain degree of credibility.

\subsection{Regression results under each Fr}

For each Fr, the author calculates its coefficient according to the above process with the following formula (7):

$$
\begin{aligned}
& C r=b_{1}+b_{2}\left(\frac{L}{B}\right)+b_{3}\left(\frac{B}{T}\right)+b_{4}\left(C_{b}\right)+b_{5}\left(\frac{L}{B}\right)\left(C_{b}\right) \\
& +b_{6}\left(\frac{B}{T}\right)\left(C_{b}\right)+b_{7}\left(\frac{B}{T}\right)^{2}+b_{8}\left(C_{b}\right)^{2}
\end{aligned}
$$

\begin{tabular}{|l|l|l|l|l|}
\hline num & $C_{b}$ & $\begin{array}{l}\text { Original } \\
\text { data }\end{array}$ & $\begin{array}{l}\text { Regressio } \\
\text { n data }\end{array}$ & Error \\
\hline 3 & 0.83 & 3.049 & 3.147 & $3.22 \%$ \\
\hline 4 & 0.8375 & 3.2602 & 3.3128 & $1.61 \%$ \\
\hline 6 & 0.7505 & 3.198 & 3.2426 & $1.40 \%$ \\
\hline 7 & 0.765 & 3.2218 & 3.1851 & $-1.14 \%$ \\
\hline 8 & 0.8012 & 3.0935 & 3.1592 & $2.12 \%$ \\
\hline 9 & 0.8315 & 2.9688 & 2.9768 & $0.27 \%$ \\
\hline 10 & 0.833 & 3.2903 & 3.1412 & $-4.53 \%$ \\
\hline 11 & 0.771 & 3.067 & 3.0258 & $-1.34 \%$ \\
\hline 12 & 0.7694 & 3.264 & 3.33 & $2.02 \%$ \\
\hline 13 & 0.7727 & 3.2443 & 3.2506 & $0.19 \%$ \\
\hline 14 & 0.7968 & 3.1749 & 3.2735 & $3.10 \%$ \\
\hline 15 & 0.843 & 3.5982 & 3.5832 & $-0.42 \%$ \\
\hline 16 & 0.8332 & 3.4475 & 3.4068 & $-1.18 \%$ \\
\hline 17 & 0.7906 & 3.2968 & 3.2456 & $-1.55 \%$ \\
\hline 19 & 0.8275 & 3.4281 & 3.3731 & $-1.60 \%$ \\
\hline 20 & 0.7822 & 3.0962 & 3.1178 & $0.70 \%$ \\
\hline 21 & 0.8421 & 3.5497 & 3.5838 & $0.96 \%$ \\
\hline 22 & 0.8206 & 3.0303 & 3.0273 & $-0.10 \%$ \\
\hline 23 & 0.7853 & 3.331 & 3.3103 & $-0.62 \%$ \\
\hline 24 & 0.8075 & 3.3 & 3.363 & $1.91 \%$ \\
\hline 25 & 0.809 & 3.199 & 3.2205 & $0.67 \%$ \\
\hline 26 & 0.7822 & 3.423 & 3.2558 & $-4.88 \%$ \\
\hline
\end{tabular}

After repeating linear regression and eliminating the abnormal point, the following table 3 is finally obtained. This result makes RMSE, the statistical value $F$ and the corresponding probability $\mathrm{p}$ meet certain requirements.

Table.3 Regression Equation Coefficients under Each Fr

\begin{tabular}{|c|c|c|c|c|}
\hline coefficients & 0.15 & 0.16 & 0.17 & 0.18 \\
\hline b1 & 4.428 & 22.312 & 42.181 & 68.047 \\
\hline b2 & 7.357 & 4.917 & 0.865 & -3.602 \\
\hline b3 & 5.101 & 2.964 & 1.390 & -1.821 \\
\hline b4 & -95.222 & -108.53 & -119.55 & -131.96 \\
\hline b5 & -9.676 & -6.810 & -1.840 & 3.688 \\
\hline b6 & -4.120 & -1.690 & 0.135 & 4.015 \\
\hline b7 & -0.186 & -0.172 & -0.164 & -0.161 \\
\hline b8 & 110.426 & 101.578 & 85.696 & 62.175 \\
\hline coefficients & 0.19 & 0.2 & 0.21 & 0.22 \\
\hline b1 & 101.256 & 82.135 & 134.723 & 127.868 \\
\hline b2 & 13.241 & -2.609 & -6.901 & 5.497 \\
\hline b3 & -2.946 & -0.790 & -4.849 & -0.570 \\
\hline b4 & -140.22 & -181.46 & -257.17 & -352.75 \\
\hline b5 & 16.021 & 2.161 & 7.405 & -9.256 \\
\hline b6 & 4.728 & 3.398 & 8.382 & 6.022 \\
\hline b7 & -0.099 & -0.208 & -0.215 & -0.466 \\
\hline b8 & 20.698 & 102.156 & 116.668 & 246.722 \\
\hline
\end{tabular}

It can be seen from above the constant term in the formula increases gradually, which determines that $\mathrm{Cr}$ 
will show an increasing trend with the increase of Fr. While the coefficients containing only $\mathrm{Cb}$ terms (namely b4 and b8) have larger absolute values, which shows a greater impact on the rest resistance.

\section{Calculation example analysis}

The DTMB5415 selected in this paper is a preliminary design of a warship in Taylor tank around 1980. It has a bow sonar housing and a square stern. The main dimension parameters are shown in Table 4 below.

Tab.4 Main Dimension Parameters

\begin{tabular}{|c|c|}
\hline Parameters & values \\
\hline $\mathrm{L}_{\mathrm{pp}} / \mathrm{m}$ & 5.72 \\
\hline $\mathrm{B} / \mathrm{m}$ & 0.76 \\
\hline $\mathrm{T} / \mathrm{m}$ & 0.248 \\
\hline $\mathrm{S} / \mathrm{m}^{2}$ & 4.861 \\
\hline $\mathrm{Cb}$ & 0.506 \\
\hline $\mathrm{Re}$ & $1.26^{*} 10^{7}$ \\
\hline$\lambda$ & 24.8 \\
\hline
\end{tabular}

In my previous study on the optimization of trimaran layout $^{[3]}$, the drag coefficient of the model under each $\mathrm{Fr}$ was simulated and it is shown in Figure 4 below.

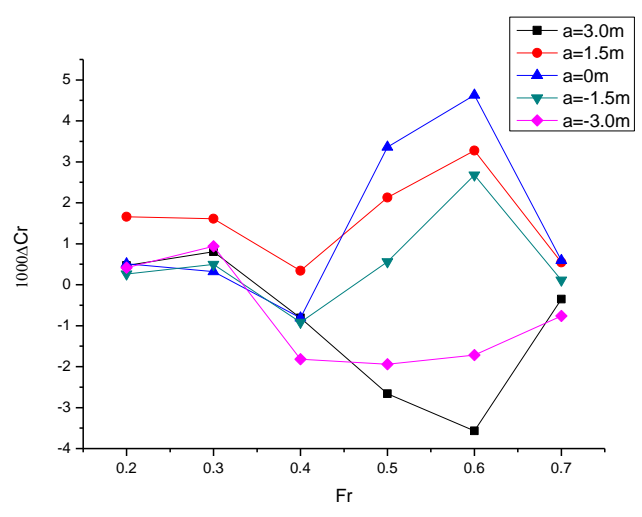

Fig. 4. Cr of Trimaran in Different Layouts

In my previous study on the optimization of trimaran layout, the coefficient of this model under each Fr was simulated. Firstly, take the optimal layout (the side hull $1.5 \mathrm{~m}$ behind the main hull) in my simulation results. And then, the regression calculation value of the monohull is converted into $\mathrm{Ct}$ of the trimaran. Finally, after comparing the CFD simulation results with the regression prediction value, it is found that the error is within $10 \%$ in the following Table.5.

The main reasons for the error are as follows: (1) Because the theoretical analysis method fails to take into account the influence of the main and side hull interference on the rapid performance of the trimaran. (2) Due to the certain differences in the number of sample and ship types, the regression formula has a certain limitations.
Tab.5 Contrast Error

\begin{tabular}{|c|c|c|c|}
\hline $\mathrm{Ct}^{*} 10^{3}$ & $\mathrm{Fr}=0.2$ & $\begin{array}{c}\mathrm{Fr}=0.2 \\
5\end{array}$ & $\mathrm{Fr}=0.3$ \\
\hline $\begin{array}{c}\text { CFD simulation } \\
\text { results }\end{array}$ & 4.57 & 4.66 & 4.91 \\
\hline $\begin{array}{c}\text { regression } \\
\text { prediction value }\end{array}$ & 4.28 & 4.51 & 4.79 \\
\hline error & $6.77 \%$ & $3.33 \%$ & $2.50 \%$ \\
\hline
\end{tabular}

\section{Conclusion}

For the resistance prediction of the trimaran, the experimental method is undoubtedly accurate, but the cost is relatively high. The simulation method is also very common, and the interference between the main and side hull is also involved. But the modeling workload is relatively large and the conclusion is affected by the quality of the grid. The regression method involved in my article can be used in the preliminary design stage to estimate the resistance value quickly and roughly. The above case proved that the numerical error is not too large. This method has certain reference value, which can predict the resistance performance of the ship.

Compared with the typical CFD calculation, the method of multiple regression saves a lot of time on the basis of close accuracy, and the ability of both the sample simulation and the large-range prediction is much better than the CFD simulation. To some extent, it can be used as an effective means to predict ship resistance performance in the early stage.

\section{Acknowledgement}

PROGRAM: Hubei Provincial Department of Education Scientific Research Guidance Progrom (num as B2018341)

\section{References}

1. Lars Larsson, Frederick Stern and Volker Bertram. Benchmarking of Computational Fluid Dynamics for Ship Flows: The Gothenburg 2000 Workshop. Lowa City. USA. 2003.

2. Leonardo Di Gangi,M. Lapucci,F. Schoen,A. Sortino. An efficient optimization approach for best subset selection in linear regression, with application to model selection and fitting in autoregressive time-series[J]. Computational Optimization and Applications,2019,74(3)

3. Xiao Ying Xu, YAN Hong Sheng, LIU Feng Di. Tension hybrid optimization algorithm for automatic mooring positioning system[J]. Ship Engineering, 2013(04) (in Chinese)

4. Zhen Bang Sheng, Principles of Ships. Shanghai Jiaotong University Press. 2020.7 (in Chinese) 